\title{
Al6061 Reinforced A12O3 Metal Matrix Composite Produced by Double Blade Stir Casting
}

\author{
Anne Zulfia $^{\# 1}$, Krista Raga ${ }^{\#}$, Wahyuaji Narottama ${ }^{\#}$, Salahuddin Yunus ${ }^{* 4}$ \\ ${ }^{\#}$ Department of Metallurgy and Material, Faculty of Engineering, Universitas Indonesia, Depok 16424, Indonesia \\ E-mail:1anne@metal.ui.ac.id \\ *Department of Mechanical Engineering, Faculty of Engineering, Jember University, Jawa Timur 68121, Indonesia \\ E-mail: salahuddin.yunus@gmail.com
}

\begin{abstract}
Demand for materials with excellent mechanical properties and lightweight increase in a recent year especially for highperformance applications. Aluminum reinforced $\mathrm{Al}_{2} \mathrm{O}_{3}$ composite (AMC) provide this superior property. Therefore in this research, aluminum alloy 6061 was used as a matrix and $\mathrm{Al}_{2} \mathrm{O}_{3}$ with 10 and $15 \mathrm{Vf}-\%$ as a reinforced for making metal matrix composites while magnesium as a wetting agent was used various from 8,10 to 15 wt-\% to improve the wettability between $\mathrm{Al}^{2}$ and $\mathrm{Al}_{2} \mathrm{O}_{3}$ since aluminum was poor wetting with ceramic. $\mathrm{Al}$ alloy 6061 was melted at $800{ }^{\circ} \mathrm{C}$ and magnesium was added into $\mathrm{Al}$ molten, then $\mathrm{Al}_{2} \mathrm{O}_{3}$ particles were poured into the melt. The process using double stirrer with a rotational speed of $1000 \mathrm{rpm}$ for 3 minutes to distribute all $\mathrm{Al}_{2} \mathrm{O}_{3}$ particles in the $\mathrm{Al}$ melt and all the gas bubble formed was removed by flushing an Argon for 2 minutes. The composites produced then characterized both mechanical properties and microstructural analysis. The focus of this research is to investigate the effect of $\mathrm{Al}_{2} \mathrm{O}_{3}$ and $\mathrm{Mg}$ on the mechanical properties of composites. The result showed that the optimum tensile strength was $202 \mathrm{MPa}$ which was obtained in composite with $10 \% \mathrm{Vf}-\% \mathrm{Al}_{2} \mathrm{O}_{3}$ and $10 \mathrm{wt}-\% \mathrm{Mg}$. Moreover, hardness and wear resistant to composite increased with the addition of $\mathrm{Al}_{2} \mathrm{O}_{3}$ and $\mathrm{Mg}$ content due to good wetting in composites with 10 wt-\% Mg. The double blade stirrer has contributed to the random distribution of $\mathrm{Al}_{2} \mathrm{O}_{3}$ particles in the molten $\mathrm{Al}$. The microstructure observations showed that the composites yield pores and impaired the mechanical properties of composites.
\end{abstract}

Keywords — aluminum composite; $\mathrm{Al}$ alloy $6061 ; \mathrm{Al}_{2} \mathrm{O}_{3}$ particles; magnesium; double blade stir casting.

\section{INTRODUCTION}

Metal-matrix composites (MMCs) as a candidate material in the future due to lightweight and strength for broad application. This material has been developed by other researches [1]-[3]. In this category, the ceramics can be used as a reinforcement in MMCs to improve their properties including tensile strength, hardness, wear resistance, and excellent corrosion resistance. MMCs is a combination of ductility of metallic matrix alloys with high strength of ceramic reinforcements and lead to higher strength both tension and compression as well as higher service temperature capabilities. Due to these properties, MMCs has been used for an automotive application. There are some techniques for making MMCs materials, depending on the reinforced and matrix; the techniques may vary considerably. These techniques are classified into liquid phase or casting processes, liquid-solid processes, and solidstate processes or powder metallurgy [3]-[5]. Among those process, stir casting is widely used for making MMCs. This process allows a conventional metal processing route to be used, hence minimizes the final cost of the product, and significant sized components can be fabricated. There is some method of stirrer including single and double stirrer as well as up-down. There are some factors that should be concerned in casting composites [5]: (i) The particles reinforced distribution is difficult to be (ii) Wettability between particles reinforced and matrix, (iii) Porosity or void formation in the interface (iv) Chemical reactions between the reinforcement material and the matrix alloy.

Therefore, wettability plays an essential role in order to improve the mechanical properties of the metal matrix composite. Besides wetting, the distribution of the reinforced was also important therefore stirrer is useful to distribute the particles reinforced in the molten metal. There is a problem found in making metal matrix composite such as settling of the reinforcement particles during casting that caused cluster distribution which impairs the mechanical properties of composites. The mechanical stirrer used should be made by ceramic which resists at the melting temperature of the metal. The stirring speed should not be too high but should be continuous for a few minutes before the metal melt is 
poured into a mold through the bottom of the crucible. The vortex formation during stirring is used to create and maintain the proper distribution of the reinforcement in the molten matrix alloy [6].

Technically, stirring helps in distribution all particles into the liquid metal homogenously and maintaining the particles reinforced in suspension. On the other hand, air bubbles and all the other impurities on the surface of the melt could be trapped in the liquid, therefore, remaining porosity and inclusions in the cast product. To remove all air bubbles in the liquid metal so, an inert gas such as argon or nitrogen must be flushed. The successful MMCs was formed when liquid can spread correctly on a solid surface. It was described by wetting between molten metal and solid ceramic. The proposition of the wetting of the ceramic by molten metal is one of surface chemistry and surface tension, therefore magnesium was added to reduce the surface tension of Al melts [7]. This wetting agent can reduce the surface tension of metal melts and hence wet the ceramic particles to form an interface zone. It also forms some phase in the particle-matrix interface, which removes oxygen on reinforcing particle surface. In this study, Al6061/ $\mathrm{Al}_{2} \mathrm{O}_{3}$ metal matrix composites will be carried out by double blade stir casting, and the effect of $\mathrm{Mg}$ and $\mathrm{Al}_{2} \mathrm{O}_{3}$ on mechanical properties as well as microstructural analysis will be investigated.

\section{MATERIAL AND METHOD}

\section{A. Research Materials}

The materials used in this work were Al6061 as a matrix, $\mathrm{Al}_{2} \mathrm{O}_{3}$ with the particles size of $60 \mu \mathrm{m}$ as a reinforcement and $\mathrm{Mg}$ as a wetting agent. The composition of Al6061 is in Table 1 .

TABLE I

The Composition OF Al 6061 (WT.-\%)

\begin{tabular}{|c|c|c|c|}
\hline $\mathrm{Al}$ & 95.2 & $\mathrm{Cr}$ & 0.062 \\
\hline $\mathrm{Si}$ & 0.798 & $\mathrm{Fe}$ & 0.194 \\
\hline $\mathrm{Mg}$ & 3.07 & $\mathrm{Zn}$ & 0.003 \\
\hline $\mathrm{Cu}$ & 0.275 & $\mathrm{Mn}$ & 0.023 \\
\hline $\mathrm{Ni}$ & 0.094 & $\mathrm{Sn}$ & 0.069 \\
\hline $\mathrm{Ti}$ & 0.015 & & \\
\hline
\end{tabular}

Al6061 reinforced $\mathrm{Al}_{2} \mathrm{O}_{3}$ composite was produced by a stir casting method using double blade stirrer. The amount of $\mathrm{Al}_{2} \mathrm{O}_{3}$ was $10 \mathrm{vf}-\%$, and $15 \mathrm{vf}-\%$ and $\mathrm{Mg}$ varied from 8,10 and $15 \mathrm{wt}-\%$ respectively to improve the wetting system between $\mathrm{Al} 6061$ and $\mathrm{Al}_{2} \mathrm{O}_{3}$ particles reinforced.

\section{B. Research Method}

The casting process using the electric furnace which is heated until the temperature achieved $750^{\circ} \mathrm{C}$, while $\mathrm{Al}_{2} \mathrm{O}_{3}$ was heated at $1050^{\circ} \mathrm{C}$ to remove all of the moisture. After all Al6061 alloy were completely melted then $\mathrm{Al}_{2} \mathrm{O}_{3}$ prepared was poured into the molten Al. The melt was degassed using Ar gas and then was stirred using double blade stirrer coated by zirconia with a rotational speed of $500 \mathrm{rpm}$ for 2 to 3 minutes. The melt would become more viscous because of the reinforcement particles were distributed inside it. The melt then poured into a permanent tensile test mold.

\section{Characterization of materials}

The tensile test specimens were prepared from the mold has dimensions of $32 \mathrm{~mm}$ of gage-length and $6 \mathrm{~mm}$ of diameter following ASTM E8 standard. Other characterizations such as hardness and wear tests were also measured. Density and porosity of composites were measured following densitometry method. To observe the microstructure and phases of the composite, the specimens were prepared by using metallographic preparation. First, the specimens were ground using 80, 120, 240, 500, 700, 1000, 1200 grit of emery papers, then they were mechanical polished and finally cleaned with water. The samples then analysed by Field Emission-Scanning Electron (FESEM) link to Energy Dispersive Spectra (EDS), to identify the formation of the phases in the composites.

\section{RESULTS AND DISCUSSION}

\section{A. Effect of Al2O3 Particles and Magnesium on Mechanical Properties of Al6061/ Al2O3 Metal Matrix Composites.}

The mechanical properties of $\mathrm{Al} 6061 / \mathrm{Al}_{2} \mathrm{O}_{3}$ metal matrix composites are shown in Fig. 1, including tensile strength, hardness, and wear rate.

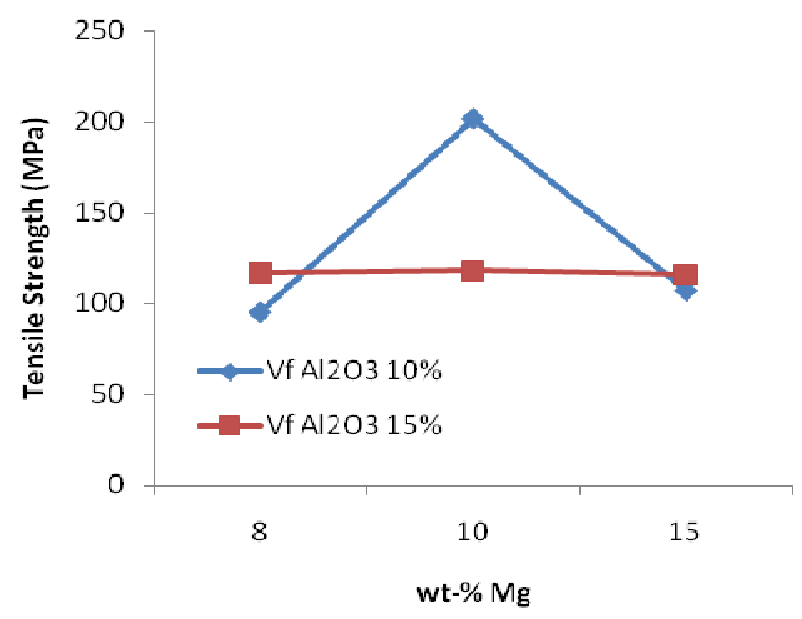

(a)

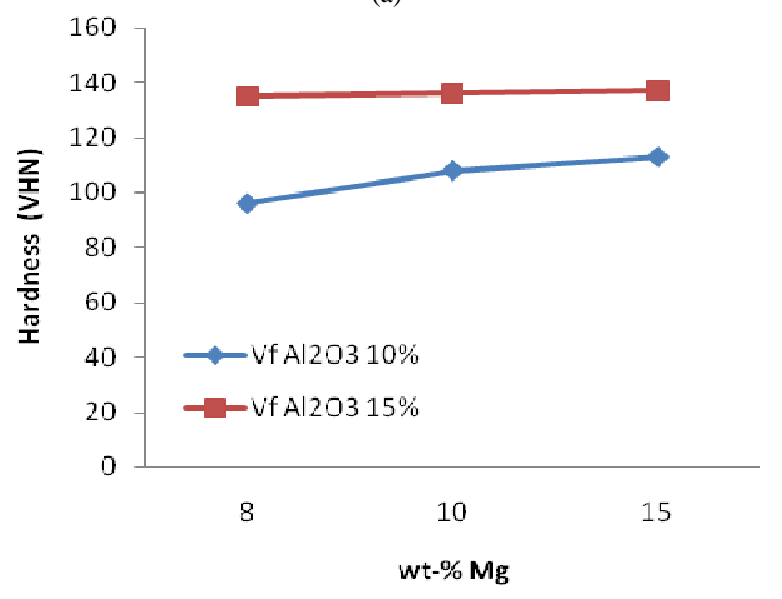

(b) 


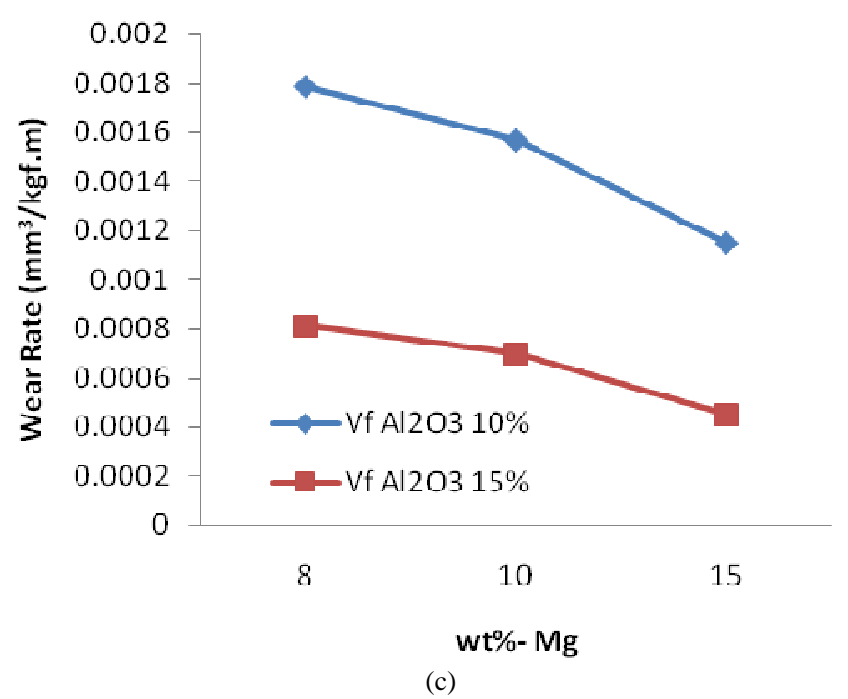

Fig.1 Effect of $\mathrm{Mg}$ on mechanical properties of $\mathrm{Al} 6061 / \mathrm{Al}_{2} \mathrm{O}_{3}$ metal matrix composites produced by double blade stir casting. a) Tensile strength, b) Hardness, c) Wear rate.

The optimum tensile strength is obtained at $10 \mathrm{wt}-\% \mathrm{Mg}$ and $10 \mathrm{vf}-\% \mathrm{Al}_{2} \mathrm{O}_{3}$ with the value of $202 \mathrm{MPa}$ (see Fig. 1a). The composites with $15 \mathrm{vf}-\% \mathrm{Al}_{2} \mathrm{O}_{3}$ showed that the tensile strength is slightly increased with increasing of $\mathrm{Mg}$, but the value was lower than composites with $10 \mathrm{wt}-\% \mathrm{Mg}$ and 10vf$\% \mathrm{Al}_{2} \mathrm{O}_{3}$. The addition of higher content of $\mathrm{Al}_{2} \mathrm{O}_{3}$, viscosity inside of the melt will become higher, and it will be harder for the viscous melt to surround the particles. This along with inherent poor wettability of the particle and will promote more porosities in the matrix where the crack will nucleate 15 vf- $\% \quad \mathrm{Al}_{2} \mathrm{O}_{3}$ and reduced strength. It is also confirmed that higher ceramic particles contained in the molten $\mathrm{Al}$ generated collision among particles and remain agglomerates or cluster distribution which impaired mechanical properties [8] (also see Fig.3). This such trend is also found in other investigation for nano $\mathrm{Al}_{2} \mathrm{O}_{3}$ [9]-[12].

The hardness of composites in Fig $1 \mathrm{~b}$ showed that increasing of $\mathrm{Mg}$ and $\mathrm{Al}_{2} \mathrm{O}_{3}$ generated increasing hardness, this is because molten $\mathrm{Al}$ has reduced surface tension with $\mathrm{Mg}$ and the wettability between $\mathrm{Al}$ and $\mathrm{Al}_{2} \mathrm{O}_{3}$ has improved. The hardness increased with a higher content of $\mathrm{Al}_{2} \mathrm{O}_{3}$ particles since by nature this particle has much harder than that of the aluminum matrix which is also found by Mujeeb et al. [13]. The presence of new phases analyzed by EDS such as $\mathrm{Mg}_{2} \mathrm{Si}$ in the form of Chinese script is also contributed to the strength and hardness (see microstructure of composites). The wear resistance that we can determine from represents the wear volume loss of matrix alloy as a function of sliding distance, here the wear rate has a reverse correlation with the hardness of composite as shown in Fig $1 \mathrm{c}$, it means the lower wear rate the higher wear resistance

The volume loss of the composites decreases with increasing of $\mathrm{Al}_{2} \mathrm{O}_{3}$ and magnesium content. It is observed that $\mathrm{Al}_{2} \mathrm{O}_{3}$ particles increase the hardness of the composites. Furthermore, the addition of magnesium improved the wettability, so the hardness of composites increased and caused the wear rate decreased.

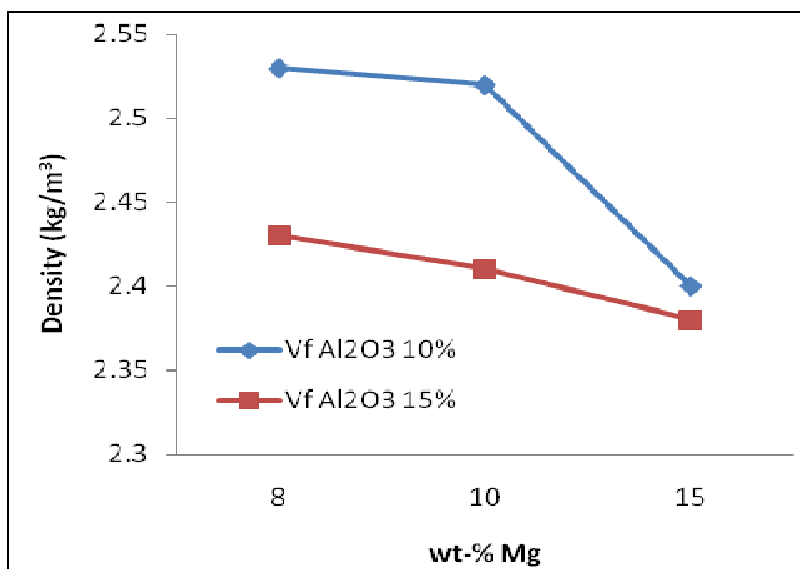

(a)

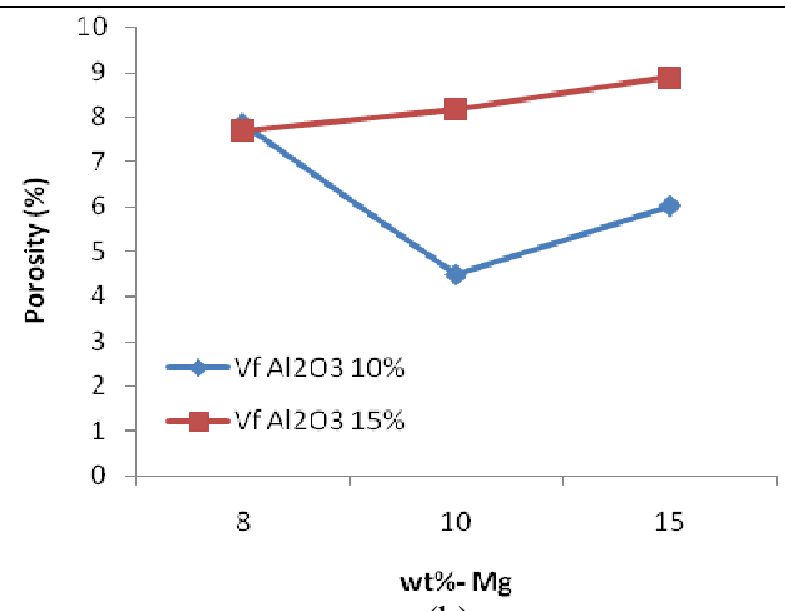

(b)

Fig. 2 Effect of Mg on density (a) and porosity (b) of $\mathrm{Al} 6061 / \mathrm{Al}_{2} \mathrm{O}_{3}$ metal matrix composites produced by double blade stir casting

The density and porosity of composites are shown in Fig. 2. The density of composites decreased with higher $\mathrm{Mg}$ content while on the contrary porosity increased. The density for composites with $10 \mathrm{vf}-\% \mathrm{Al}_{2} \mathrm{O}_{3}$ is higher than $15 \mathrm{vf}-\%$ $\mathrm{Al}_{2} \mathrm{O}_{3}$ but tend to decrease with increasing $\mathrm{Mg}$. It is assumed that density decreased and porosity increased due to some ceramic particles cannot be wetted perfectly by $\mathrm{Al}$ and remain pores. Therefore, the presence of $\mathrm{Al}_{2} \mathrm{O}_{3}$ in the aluminum matrix will be a barrier to produce a perfect bonding interface.
The formation of porosity in the composites due to: the presence of hydrogen gas in the liquid aluminum, increasing of $\mathrm{Al}_{2} \mathrm{O}_{3}$ and stirring methods. According to J. Hashim [6], the casting of metal matrix composites will be present in the hydrogen gas in a liquid. This gas will be drawn into the mixing stage and entrapped in the liquid $\mathrm{Al}$ then porosity produced (also seen Fig. 5) 

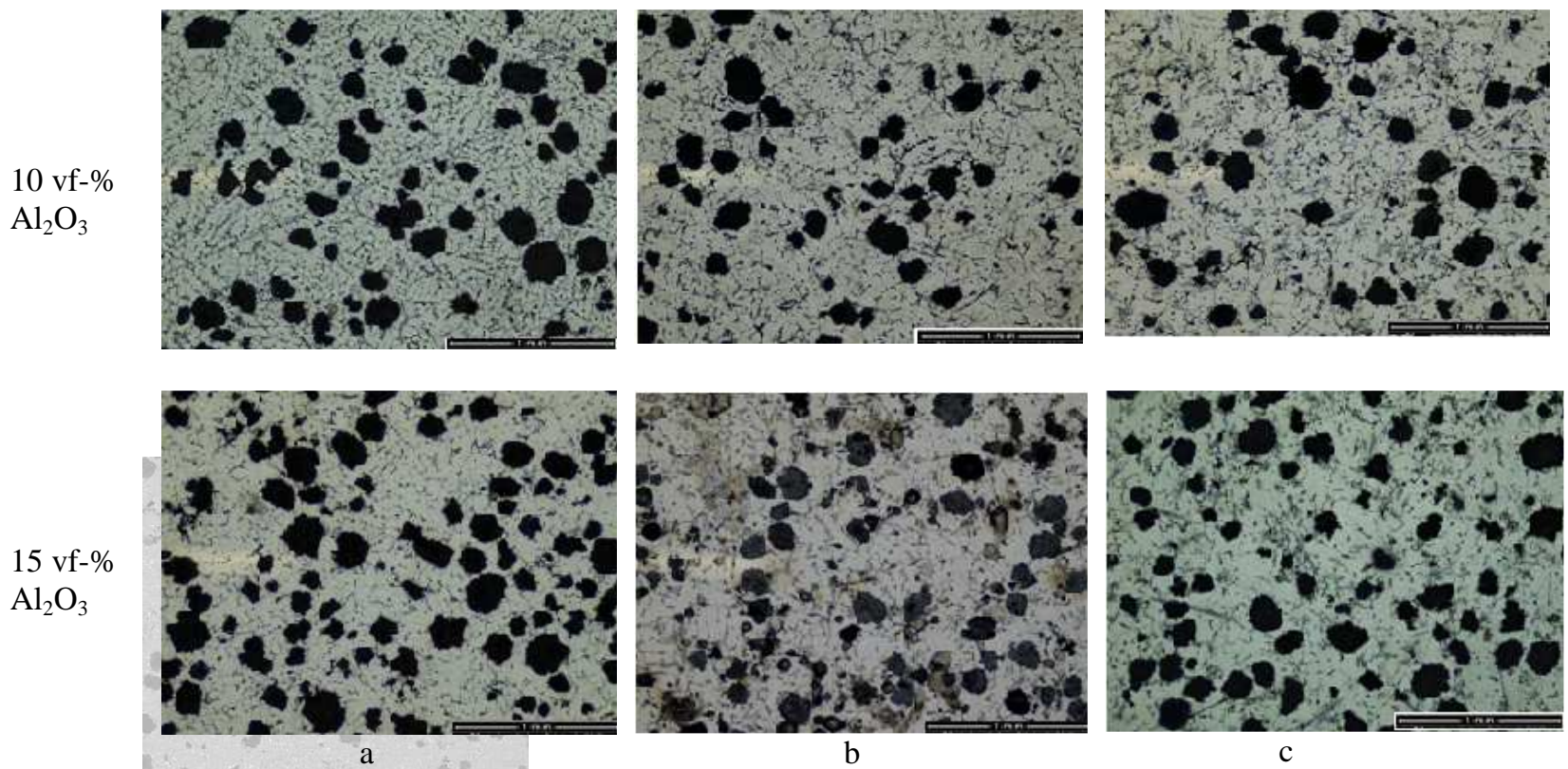

Fig. 3 Distribution of $\mathrm{Al}_{2} \mathrm{O}_{3}$ particles with different $\mathrm{Mg}$ and $\mathrm{Al}_{2} \mathrm{O}_{3}$ content in an $\mathrm{Al} 6061$ matrix on metal matrix composites produced by double blade stir casting. a) $8 \mathrm{wt}-\% \mathrm{Mg}$, b) $10 \mathrm{wt}-\% \mathrm{Mg}$ and c) $15 \mathrm{wt}-\% \mathrm{Mg}$

\section{B. Microstructural analysis of Al6061/ Al2O3 Metal Matrix composites.}

The distribution of $\mathrm{Al}_{2} \mathrm{O}_{3}$ on $\mathrm{Al} 6061$ matrix is seen to be a random distribution, and double blade stirring has contributed to distribute $\mathrm{Al}_{2} \mathrm{O}_{3}$ particles well as shown in Fig. 3 for both composites with 10 vf- $\%$ and $15 v f-\% \mathrm{Al}_{2} \mathrm{O}_{3}$ and different of $\mathrm{Mg}$ content respectively. The microstructure of the $\mathrm{Al}$ matrix is consist of $\alpha$ - $\mathrm{Al}$ dendrite which surrounded by $\mathrm{Si}$ eutectic as seen in Fig.4a. Higher vf-\% $\mathrm{Al}_{2} \mathrm{O}_{3}$ generated higher grain refinement of $\alpha-\mathrm{Al}$, and $\mathrm{Si}$ eutectic due to $\mathrm{Al}_{2} \mathrm{O}_{3}$ particles hindered the dendrite growth. According to Mandal et al. [10], the finer dendrites in the matrix could increase the tensile strength and hardness which is in line with the result of present work, except the tensile strength for composites with $10 \mathrm{wt}-\% \mathrm{Mg}$ and $15 \mathrm{Vf}-$ $\% \mathrm{Al}_{2} \mathrm{O}_{3}$.

\section{The interface of Al/Al2O3 Composites}

The interface between the $\mathrm{Al}$ matrix and $\mathrm{Al}_{2} \mathrm{O}_{3 \mathrm{p}}$ was investigated by a Scanning Electron Microscope link to EDS in Fig. 4b-d. There was a metal oxide layer formed on the surface of $\mathrm{Al}_{2} \mathrm{O}_{3 \mathrm{p}}$ which contained $\mathrm{Mg}, \mathrm{Al}, \mathrm{O}$, and $\mathrm{Si}$ elements. The metal oxide layer, such as $\mathrm{MgO}$ and $\mathrm{MgAl}_{2} \mathrm{O}_{4}$, was formed during a process where $\mathrm{Al}_{2} \mathrm{O}_{3}$ particles continued to react with Alto form $\mathrm{MgAl}_{2} \mathrm{O}_{4}$ at the interface.
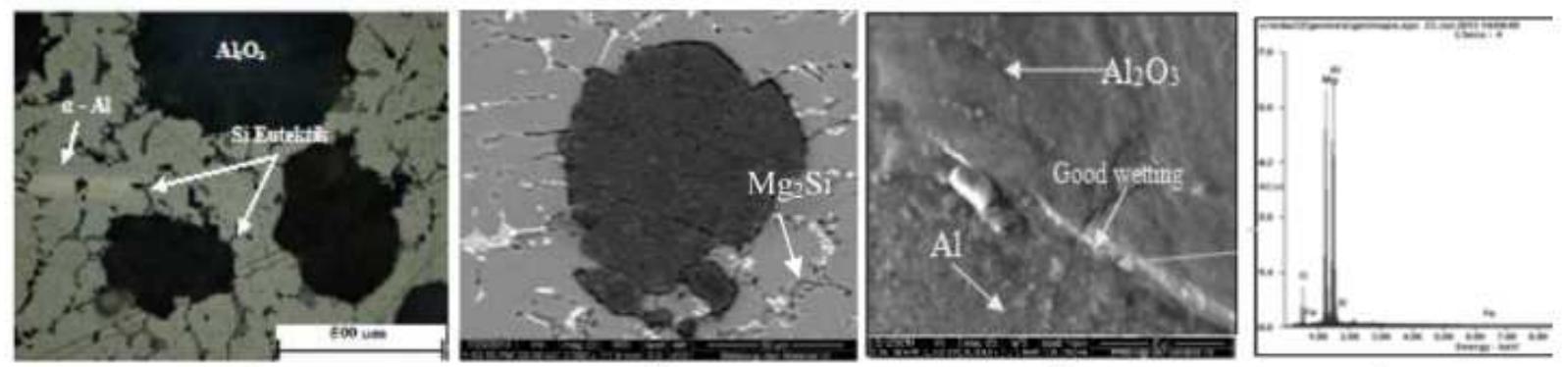

Fig. 4 Microstructure of $\mathrm{Al}_{2} \mathrm{Al}_{2} \mathrm{O}_{3}$ composites with $10 \mathrm{wt}-\% \mathrm{Mg}$ and $10 \mathrm{vf}-\% \mathrm{Al}_{2} \mathrm{O}_{3}$ taken at higher magnification. a) matrix phase, b, c ) Interface zone between $\mathrm{Al}$ and $\mathrm{Al}_{2} \mathrm{O}_{3}$, and d) EDS analysis of interface zone content in an Al6061 matrix on metal matrix composites produced by double blade stir casting

The spinel phase will reduce the surface tension of $\mathrm{Al}$ melt, so $\mathrm{Al}_{2} \mathrm{O}_{3}$ will be wetted during the stir casting process. Indeed the wetting between the $\mathrm{Al}$ matrix and $\mathrm{Al}_{2} \mathrm{O}_{3}$ is good enough for composites with $10 \mathrm{wt}-\% \mathrm{Mg}$ and $10 \mathrm{vf}-\% \mathrm{Al}_{2} \mathrm{O}_{3}$.

\section{Effect of Alumina Particles and Magnesium on Microstructure}

SEM examination has been carried out to observe the microstructure of composites with high magnification. So we can see the porosity, distribution of reinforcing particle, and matrix. For this examination, we chose samples with highest UTS, which is $10 \mathrm{vf}-\% \mathrm{Al}_{2} \mathrm{O}_{3}-10 \mathrm{wt}-\% \mathrm{Mg}$. and $15 \mathrm{vf}-$ $\% \mathrm{Al}_{2} \mathrm{O}_{3}-15 \mathrm{wt}-\% \mathrm{Mg}$. Fig 5.a shows the microstructure of sample $10 \mathrm{vf}-\% \mathrm{Al}_{2} \mathrm{O}_{3}-10 \mathrm{wt}-\% \mathrm{Mg}$ and Fig 5.b shows the microstructure of sample $15 \mathrm{vf}-\% \mathrm{Al}_{2} \mathrm{O}_{3}-15 \mathrm{wt}-\% \mathrm{Mg}$ with a random distribution of particles and porosity.

It is known that porosity is considered to be one of the major factors responsible for the failure of casting alloy 
products. Therefore it is essential to determine the porosity of each sample.

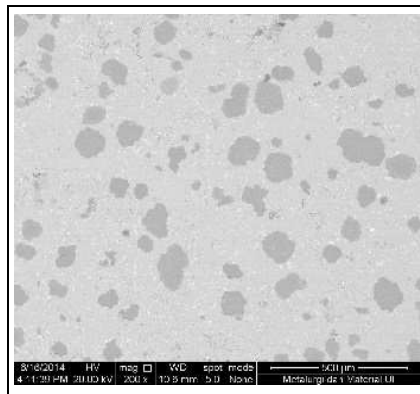

(a)

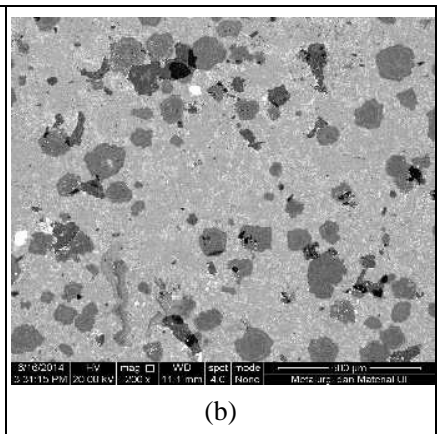

(b)
Fig.5 SEM micrograph of $\mathrm{Al} / \mathrm{Al}_{2} \mathrm{O}_{3}$ composite with 10 vf- $\% \mathrm{Al}_{2} \mathrm{O}_{3}-10$ wt- $\%$ $\mathrm{Mg}$ (a) and (b) microstructure of $\mathrm{Al} / \mathrm{Al}_{2} \mathrm{O}_{3}$ composite with 15 vf- $\% \mathrm{Al}_{2} \mathrm{O}_{3}$ $15 \mathrm{wt} \% \mathrm{Mg}$

Therefore it is essential to determine the porosity of each sample. From Fig. $2 \mathrm{~b}$ can be seen that the addition of $\mathrm{Al}_{2} \mathrm{O}_{3}$ generally increase the porosity level since $\mathrm{Al}_{2} \mathrm{O}_{3}$ particles reinforced is not perfect wetted by molten aluminum and remain porosity [14]. The porosity itself takes place due to excess hydrogen in the casting process when exciting works, especially when the method is not to vacuum, increased surface area contact with air, gas trapped during stirring see also Fig. 7, casting distance from the crucible to the mold, and shrinkage during solidification [6]. EDS analysis in Fig 6 is shown in Table 2 .

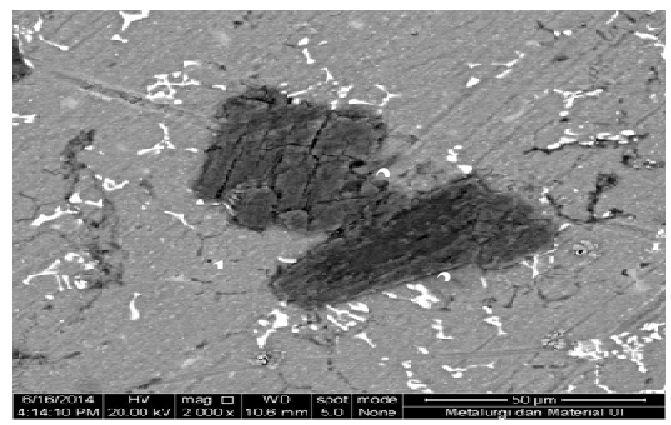

Fig. 6 SEM micrograph of $\mathrm{Al} / \mathrm{Al}_{2} \mathrm{O}_{3}$ composite with 10 vf- $\% \mathrm{Al}_{2} \mathrm{O}_{3}-10$ wt- $\%$ $\mathrm{Mg}$ link to EDS to identify phase presence in composite

TABLE II

PhaseS at InTERFACE COMPOSITE WITH 10VF-\%AL2O3-10 wT-\% Mg

\begin{tabular}{|c|r|r|r|r|c|}
\hline Spot & Al & \multicolumn{1}{|c|}{ O } & Mg & Si & Phase \\
\hline 1 & 92.48 at $\%$ & $1.82 \mathrm{Wt} \%$ & $5.42 \mathrm{Wt} \%$ & $0.28 \mathrm{Wt} \%$ & $\mathrm{Al}-\mathrm{Mg} \mathrm{Matrix}$ \\
\hline 2 & $58.59 \mathrm{at} \%$ & $33.62 \mathrm{Wt} \%$ & $7.53 \mathrm{Wt} \%$ & $0.26 \mathrm{Wt} \%$ & $\mathrm{MgAl}_{2} \mathrm{O}_{4}$ \\
\hline 3 & $64.89 \mathrm{at} \%$ & $14.85 \mathrm{Wt} \%$ & $19.93 \mathrm{Wt} \%$ & $0.33 \mathrm{Wt} \%$ & $\mathrm{MgAl}_{2} \mathrm{O}_{4}$ \\
\hline
\end{tabular}

Spot 1 is an aluminum matrix which is a content of $\mathrm{Al}$ element. The phase presence with black color in spot 2 is alumina particle which indicates in that region oxide has been formed with $58.59 \% \mathrm{Al}$ and $33.62 \%$ oxygen. The spot 3 interfaces zone of an aluminum matrix and reinforced particles with spinel phase or $\mathrm{MgAl}_{2} \mathrm{O}_{4}$. In this study, show that the $\mathrm{Al} / \mathrm{Mg}$ ratio approach to 2 . So, in this interface indicate the presence of spinel $\left(\mathrm{MgAl}_{2} \mathrm{O}_{4}\right)$.

\section{E. Fracture Surface on Al/Al2O3 Composites}

The fracture surface of $\mathrm{Al} / \mathrm{Al}_{2} \mathrm{O}_{3}$ was taken from the tensile test sample is shown in Fig. 7. The fracture of the composites was caused by porosity present in the matrix as well as poor wetting between matrix and reinforcement. Large porosity found at composites with $15 \mathrm{wt}-\% \mathrm{Mg}$ and 15 vf- $\% \mathrm{Al}_{2} \mathrm{O}_{3}$, this porosity formed because the vortex flow during mixing will draw gas into the liquid metal and stuck in the metal to form gas porosity [15].

Large porosity due to poor wetting will cause impair mechanical properties of composites. It is evident that the tensile strength of these composites decreased. The failure of composites has also involved the nucleation of crack and propagated along with the reinforcement/matrix interface [16]. The interface cracking can create a new surface at the interface between particles and matrix then remain particles deboning which caused fracture of composites which is also occurred in current work.

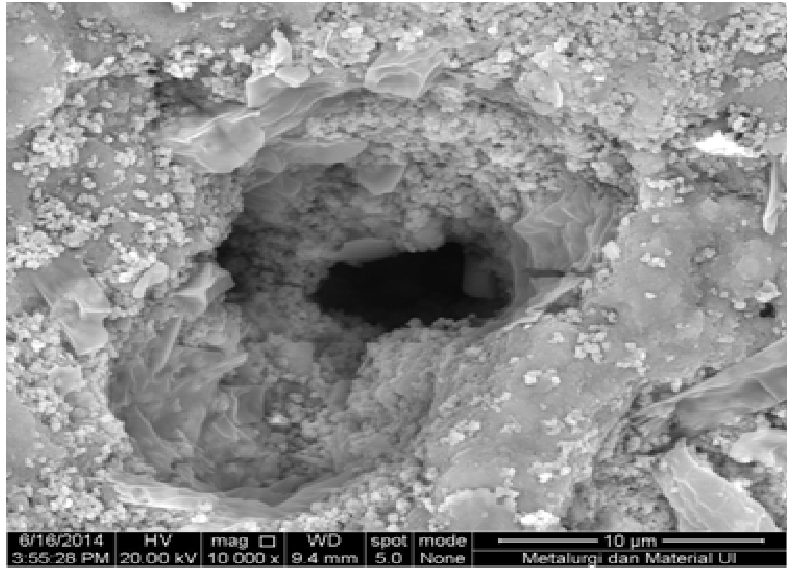

Fig.7 Fracture surface of $\mathrm{Al} / \mathrm{Al}_{2} \mathrm{O}_{3}$ composites taken from the tensile sample with $15 \mathrm{wt}-\% \mathrm{Mg}$ and $15 \mathrm{vf}-\% \mathrm{Al}_{2} \mathrm{O}_{3}$.

\section{CONCLUSIONS}

In this work, $\mathrm{Al} 6061 / \mathrm{Al}_{2} \mathrm{O}_{3}$ metal matrix composites have been successfully produced by the double blade stir casting process, and the characterization of composites can be concluded as follows: The optimum tensile strength and wear resistance of composites are obtained at $10 \mathrm{wt}-\% \mathrm{Mg}$ and 10 vf- $\% \mathrm{Al}_{2} \mathrm{O}_{3}$, while hardness and porosity increased with a higher content of $\mathrm{Al}_{2} \mathrm{O}_{3}$. The distribution of $\mathrm{Al} 2 \mathrm{O} 3$ in the Al6061 matrix is a random distribution for all composites, and double blade stirring has contributed to distributeAl2O3particles on the Al matrix well. The metal oxide layer formed in the interface is $\mathrm{MgO}$ and $\mathrm{MgAl} 2 \mathrm{O} 4$, 
as a reaction product between $\mathrm{Al} 6061$ and $\mathrm{Al} 2 \mathrm{O} 3$ generated good interface bonding between $\mathrm{Al}$ and $\mathrm{Al} 2 \mathrm{O} 3$ particularly for composites with $10 \mathrm{wt}-\% \mathrm{Mg}$ and $10 \mathrm{vf}-\% \mathrm{Al} 2 \mathrm{O} 3$.

\section{ACKNOWLEDGMENT}

Authors would like to thank the Directorate of Research and Community Services (DRPM) Universitas Indonesia, for financial support to conduct this research through International Publications Index for Final Year Students Projects Grant (PITTA), 2018 with contract No. 2378/UN2/R3.1/HKP.05.00/2018

\section{REFERENCES}

[1] W. D. Callister. "Materials Science and Engineering: An Introduction." John Wiley \& Sons, Inc. 646-688. 2007

[2] F.L. Matthews, R.D. Rawlings. "Composite Materials: Engineering and Science." Woodhead Publishing Limited 1. 473- 573. 2003

[3] J. Hashim, L. Looney, M.S.J. Hashmi. "The Wettability of SiC Particles by Molten Aluminum Alloy" Journal of Mater als Processing Technology 119. 324-328. 2001

[4] A. J. Knowles, X. Jiang, M. Galano, and F. Audebert, "Microstructure and mechanical properties of $6061 \mathrm{Al}$ alloy based composites with SiC nanoparticles," J. Alloys Compd., vol. 615. 401405. 2014.

[5] S.Pournaderi, S.Mahdavi, F.Akhlaghi, Fabrication of $\mathrm{Al} / \mathrm{Al}_{2} \mathrm{O}_{3}$ composites by in-situ powder metallurgy (IPM), Powder Technology, Vol 229. 276-284. 2012

[6] J. Hashim, L. Looney, M.S.J. Hashmi. "Metal Matrix Composites: Production by the Stir Casting Method." Journal of Materials Processing Technology 92-93 (1999) 1-7.
[7] S. Bao, K. Tang, A. Kvithyld, M. Tangstad, T.A. Engh, Wettability of Aluminum on Alumina Metallurgical and Materials Transactions B 42(6):1358-1366. 2011

[8] Hai Su, Wenli Gao, Zhaohui Feng, Zheng Lu, Processing, microstructure and tensile properties of nano-sized Al2O3 particle reinforced aluminum matrix composites. Mats and Design 36, 590596. 2012

[9] M. Kirman, A. Zulfia, Sutopo and B. Suharno, Investigation on mechanical properties of $\mathrm{AlZrCe}-\mathrm{Al}_{2} \mathrm{O}_{3}$ nanocomposites fabricated by stir casting, IOP Conf. Series: Materials Science and Engineering 58, 012009. 1-6. 2014

[10] A.Mandal, B.S. Murty, M. Chakraborty, Sliding wear behavior of T6 treated A356-TiB2 in-situ composites, Wear 266, 865-872. 2009

[11] A.Zulfia, R.P, Maulana, F.Robby, M. Kirman, and A.Sukarto, Effects Of $\mathrm{Al}_{2} \mathrm{O}_{3 n p}$ And $\mathrm{Mg}$ Addition On The PropertiesOf The $\mathrm{Al}-\mathrm{Zr}-\mathrm{Ce}$ Nanocomposite Produced by Stir Casting, As Aluminium Conductor, Powder Metallurgy and Metal Ceramics, Vol. 54, Nos. 9-10. 535542. 2016

[12] A. Zulfia, S. Junus, A.Hafeizh, Characterization of Al-Si-Mg/ $\mathrm{Al}_{2} \mathrm{O}_{3}$ Nano Composite Produced by Stir Casting Method, Materials Science Forum Vol. 827. 294-299. 2015

[13] S. Mujeeb Quader, B. S. N. Murthy, and P. Ravinder Reddy, International Journal of Engineering Studies. ISSN 0975-6469 Volume 9, Number 1. 11-19. 2017

[14] A. Zulfia, T. Zhakiah, D. Dhaneswara, Sutopo 2017 IOP Conf. Ser.: Mater. Sci. Eng. 202 012. 1-9. 2017

[15] M.K. Akbaria, O. Mirzaee, H.R. Baharvandi, Fabrication and study on mechanical properties and fracture behavior of nanometric $\mathrm{Al}_{2} \mathrm{O}_{3}$ particle-reinforced A356 composites focusing on the parameters of vortex method, Materials and Design 46. 199-205. 2013

[16] G.G. Sozhamannan, S. Balasivanandha Prabu, R. Paskaramoorthy, Failures analysis of particle reinforced metal matrix composites by microstructure-based models, Materials and Design 31. 3785-3790. 2010 